\title{
Investigation of kinematic parameters of two nonconventional piston machines with wobble board
}

\author{
Peter Baran ${ }^{1, *}$, Pavol Št'astniak ${ }^{1}$, Pavol Kukuča ${ }^{1}$, Miloš Brezáni ${ }^{1}$ \\ ${ }^{1}$ University of Žilina, Faculty of Mechanical Engineering, Department of Transport and Handling \\ Machines, Univerzitná 8215/1, 01026 Žilina, Slovak Republic
}

\begin{abstract}
Article deals with description of non-conventional mechanism FIK and mechanism with ring, which may be suitable for special applications in the engineering industry. It is possible to use not only classical crank mechanisms, but also non-conventional mechanisms in design of piston machines. Investigation of kinematic parameters of the machines is important step to know its basic movement behaviour, and from this, it is then possible to create the alternate dynamic model or force analysis. For kinematic comparison will be designed the same basic geometric conditions in both types of models. In terms of comparisons will be monitored mainly points on wobble board and the main part will be determination of piston stroke.
\end{abstract}

Keywords: Non-conventional mechanism, piston machine, kinematic analysis

\section{Mechanism with ring and FIK}

The principle of changing reciprocating motion of the pistons into a rotary motion of output shaft has both mechanisms through a swinging plate, but in a case of construction, they are not identical mechanisms.

\subsection{Mechanism with ring}

Mechanism with ring (Fig. 1) is a swinging system, which is characterized, that the centre of the swinging plate (4) acting circular motion around $z$ axis during the rotation of the shaft (1). Ring (3) is used against parallel rotation of swinging plate with shaft. Reciprocating movement of the piston (6) is transformed to the rotational movement of shaft through ball joint segments (5) [1]. This schematic and virtual representation was designed for application in type of a Stirling engine, especially for connection of ball joint segment with swinging plate. Figure 1 shows simple CAD model with basic dimensions and position of piston in default case.

\footnotetext{
${ }^{*}$ Corresponding author: peter.baran@fstroj.uniza.sk

Reviewers: Robert Grega, Krzysztof Talaśka
} 

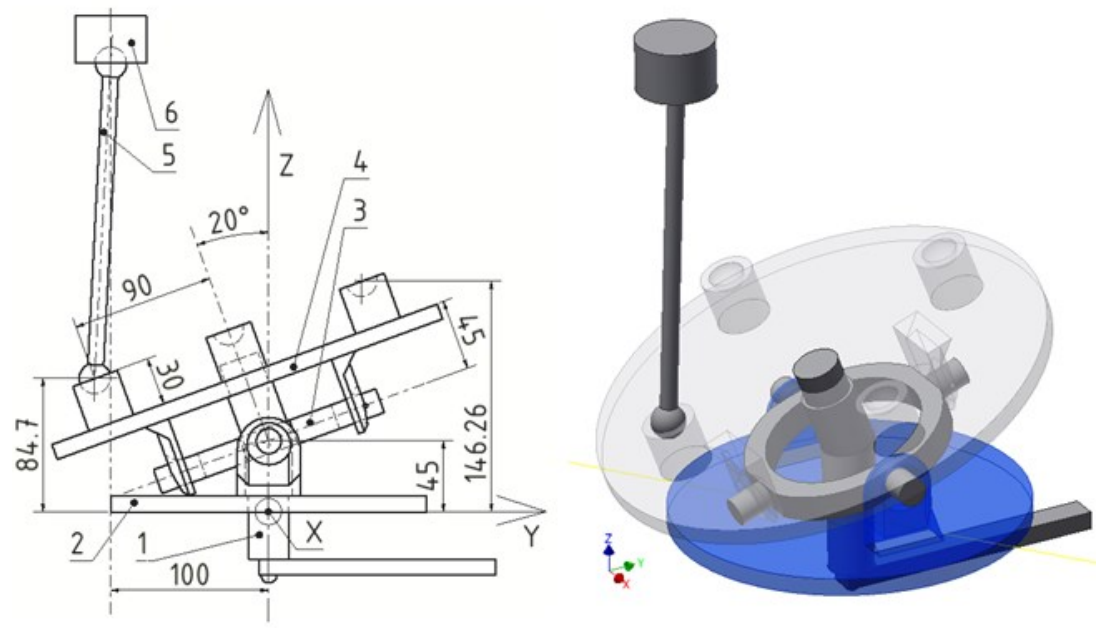

Fig. 1. Mechanism with ring - schematic representation (left side): 1 - output shaft, 2 - part of crankcase (fixed part), 3 - ring, 4 - swinging plate, 5 - ball joint segment, 6 - piston, CAD model (right side)

\subsection{Mechanism FIK}

FIK mechanism (Fig. 2) is also a swinging system. Centre (centre of gravity) of the swinging plate (4) makes circular motion during the rotation of the shaft (1). Bevel gear (3) is used against parallel rotation of swinging plate with shaft. Reciprocating movement of the pistons (6) is transformed to the rotational movement of shaft through ball joint segments (5). This schematic and virtual representation was designed for application in type of a Stirling engine, specifically for alpha configuration [1].
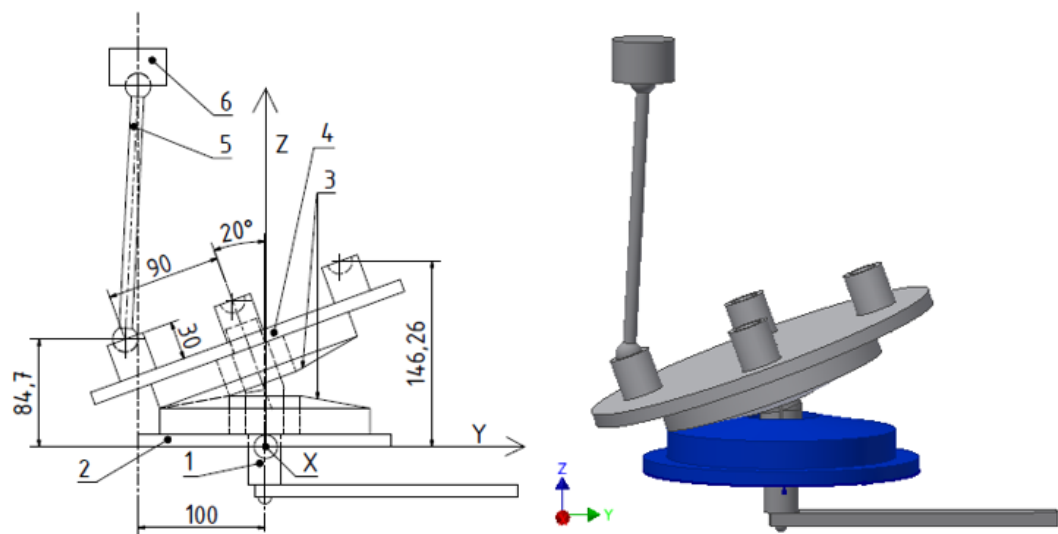

Fig. 2. Mechanism FIK: 1 - shaft, 2 - crankcase (fixed part), 3 - bevel wheels, 4 -swinging plate, 5 - ball joint segment, 6 - piston, CAD model (right side) 


\section{Initial conditions and dimensions}

The models of both mechanisms are identical in terms of dimensions (basic geometry model in Fig. 3). The kinematic analysis of the ring mechanism was created in Autodesk Inventor dynamic simulation environment and also due to verification in MSC.Adams. The FIK mechanism was created through a mathematical model.
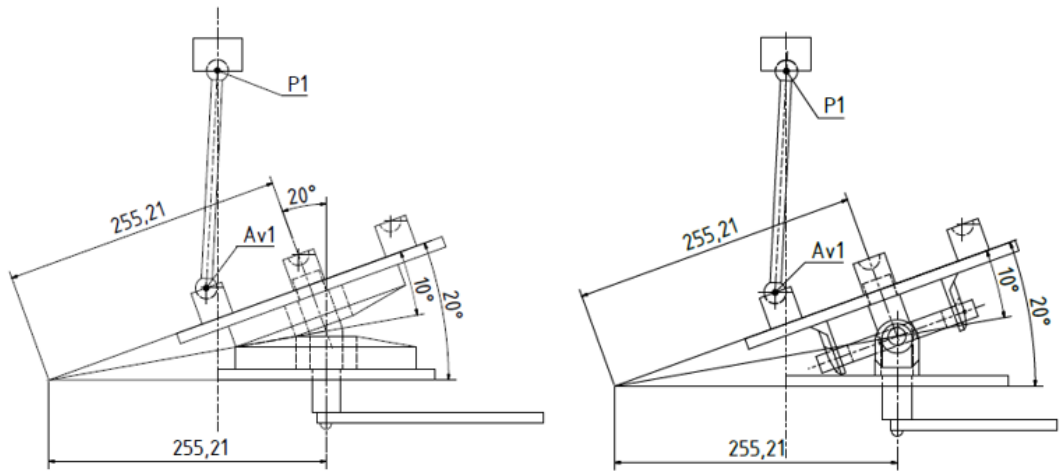

Fig. 3. Basic geometrical parameters of mechanism FIK and mechanism with ring

In a case of mechanism with a ring it was investigated five points on the board in angular range of $0-90^{\circ}$ (see Fig. 4 right side). This analysis was made because of different trajectories of these points. Mechanism FIK was investigated only as one-point model design, because of immutability with regard to the position of the given point in the same pitch diameter on swinging plate.

\subsection{Determination of points on the swinging plate}

Basic dimensions of schematic model are the most important parameters for creating a CAD model [2]. Kinematic analysis refers to the observation of the movement (in all three axes $x, y, z$ ) of five points in the swinging plate (see Fig. 4). For each of these five positions will be determined waveforms and trajectories for points Av1 and P1. During the analysis of the piston stroke was used always the same ball joint segment (distance between spherical centres is $200 \mathrm{~mm}$ ). The position of cylinder axis is also set by angular adjustment as points Av1.
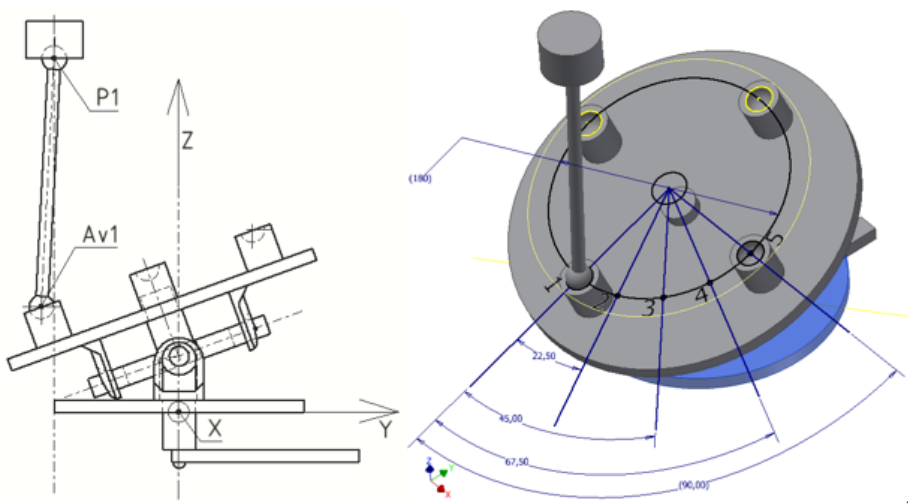

Fig. 4. Determination of five positions on swinging plate: schematic representation of examined points (left side), position of points (right side) 
Point marking (as shown in Fig. 4):

- Av1 means point on a swinging plate, point P1 is point of piston connecting part with ball joint segment.

- Av1_1 means point on a swinging plate, first position, P1_1 means point of piston first position (it is only in case of mechanism with ring, marking range from Av1_1 to Av1_5 and from P1_1 to P1_5).

- Av1_FIK and P1_FIK means marking of points in mechanism FIK.

\section{Kinematic analysis}

\subsection{Analysis of trajectories (mechanism with ring)}

The first preview of the trajectories projections in the individual planes are shown in the Fig. 5. Point markings means Av1_1 is Av1 and Av1_5 means last fifth point. From figure 5 it is possible to see differences in the courses of individual points on swinging plate.
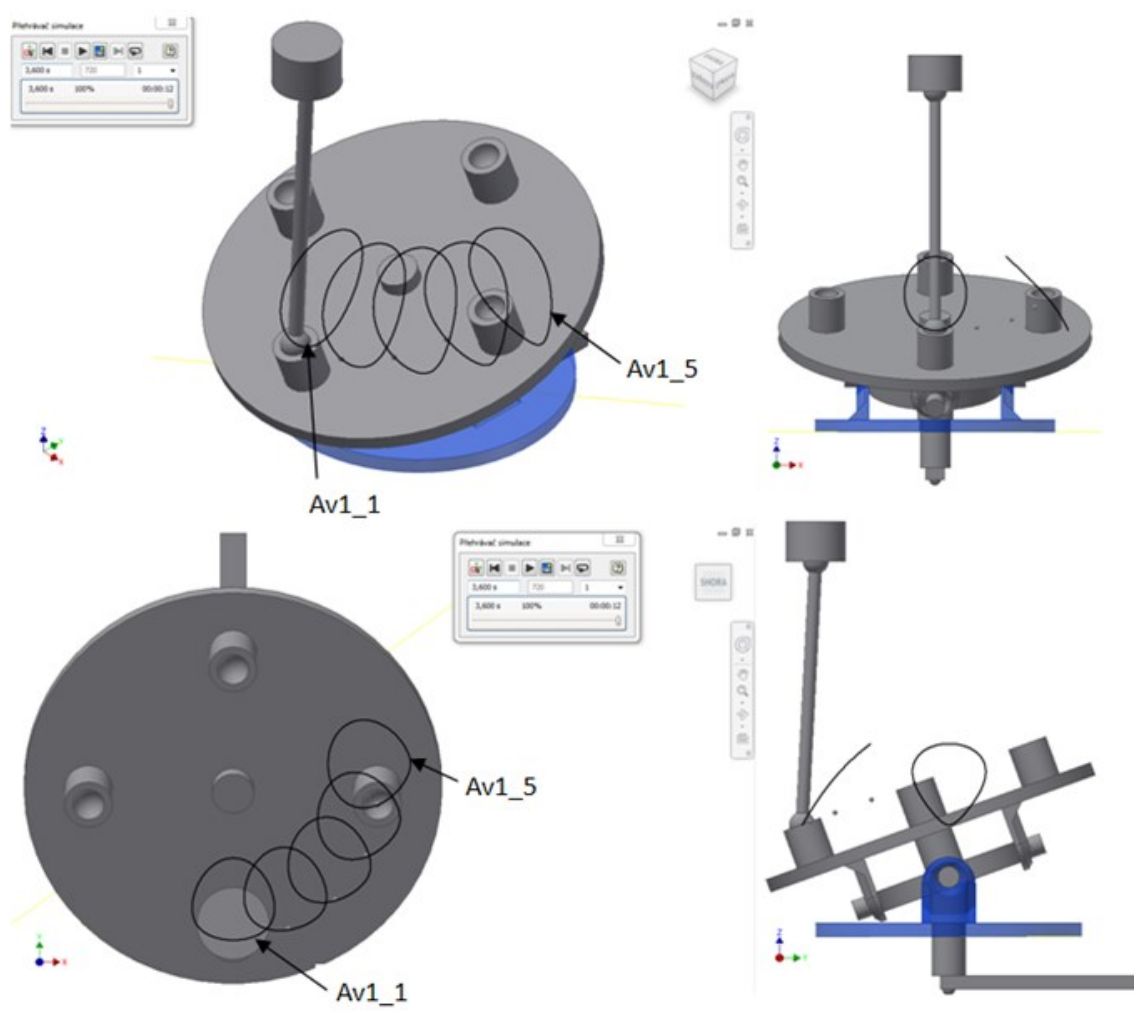

Fig. 5. Trajectories of points Av1_1 to Av1_5 (red - x, green - y, blue - z)

Setting conditions for changing the coordinate system position with grounded part of a model. In this case, the $x, y$ axes will be rotated around the $z$ axis, according to the positions of the individual points Av1_1 to Av_5, because it is easier for comparison of all waveforms. CAD model, kinematic analysis, and the courses were created in Autodesk Inventor. The simulation was set at a constant angular velocity of the output shaft and its duration was calculated to perform exactly one revolution. For the points on the swinging plate, were plotted the following projections in the individual planes (Fig. 6). 


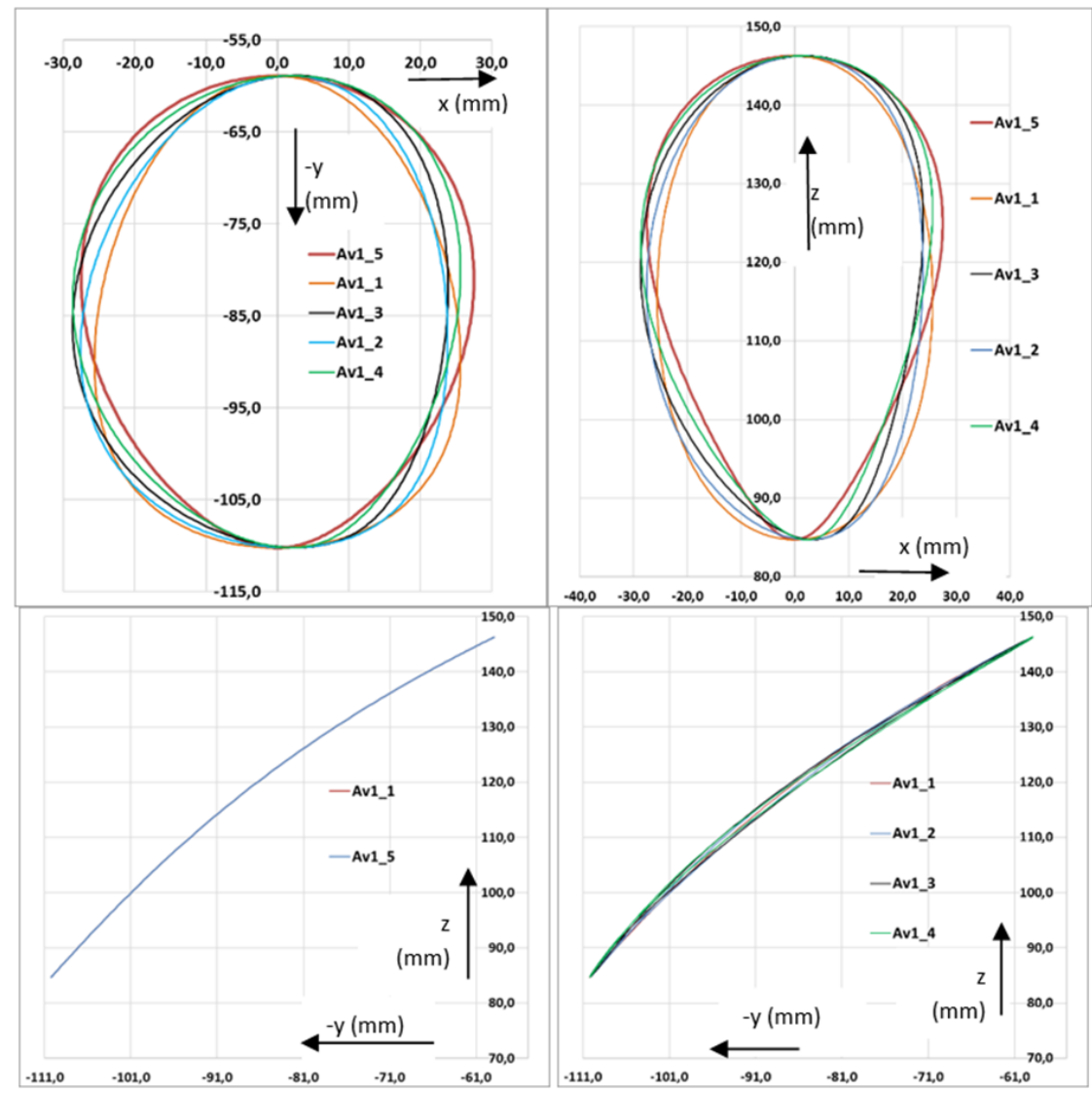

Fig. 6. Projections of trajectories of points (in millimeters) Av1_1 to Av1_5 in (at the top, from left side of picture) $\mathrm{x}-(-\mathrm{y}), \mathrm{x}-\mathrm{z}$ and $\mathrm{z}-\mathrm{y}$ plane (at the bottom)

\subsection{Analysis of trajectories (mechanism FIK)}

In this case, the model was described by mathematical equations (detailed description is in literature [1], pages 122-127). Movement of point Av1 is described by equations 1, 2, 3 (Cartesian coordinate system).

$$
\begin{gathered}
1 x=\sin \alpha \cdot\left(R_{k o} \cdot \cos \alpha-R\right) \cdot(1-\cos \varphi) \\
y=\left(R \cdot \cos \alpha+R_{k o} \cdot \sin ^{2} \alpha\right) \cdot(1-\cos \varphi)+R_{k o} \cdot \cos \varphi \\
z=\left(R-R_{k o} \cdot \cos \alpha\right) \cdot \sin \varphi
\end{gathered}
$$

The resulting equation for calculating the stroke of point $\mathrm{P} 1$ is [1]:

$$
z_{p}=z+\sqrt{l_{0}^{2}-\left(x_{o v}-x\right)^{2}-\left(y_{o v}-y\right)^{2}}
$$

Where:

- $\quad \alpha$ - rotation angle of shaft,

- $\quad R$ - radius of base rolling cone (see Fig. 3, distance 255,21 mm), 
- $\quad R_{k o}$ - distance between angle cranked axis of shaft and centre of lower ball joint centre (Fig. 2, distance $90 \mathrm{~mm}$ ),

- $\varphi$ - angle between main axis and axis of cranked part of the shaft (by Fig. 2 model, $20^{\circ}$ ),

- $\quad l_{0}$ - length of ball joint segment (length of the connecting rod),

- $\quad x_{o v}, y_{o v}$ - position in coordinates of the cylinder axis in the $x-y$ plane.
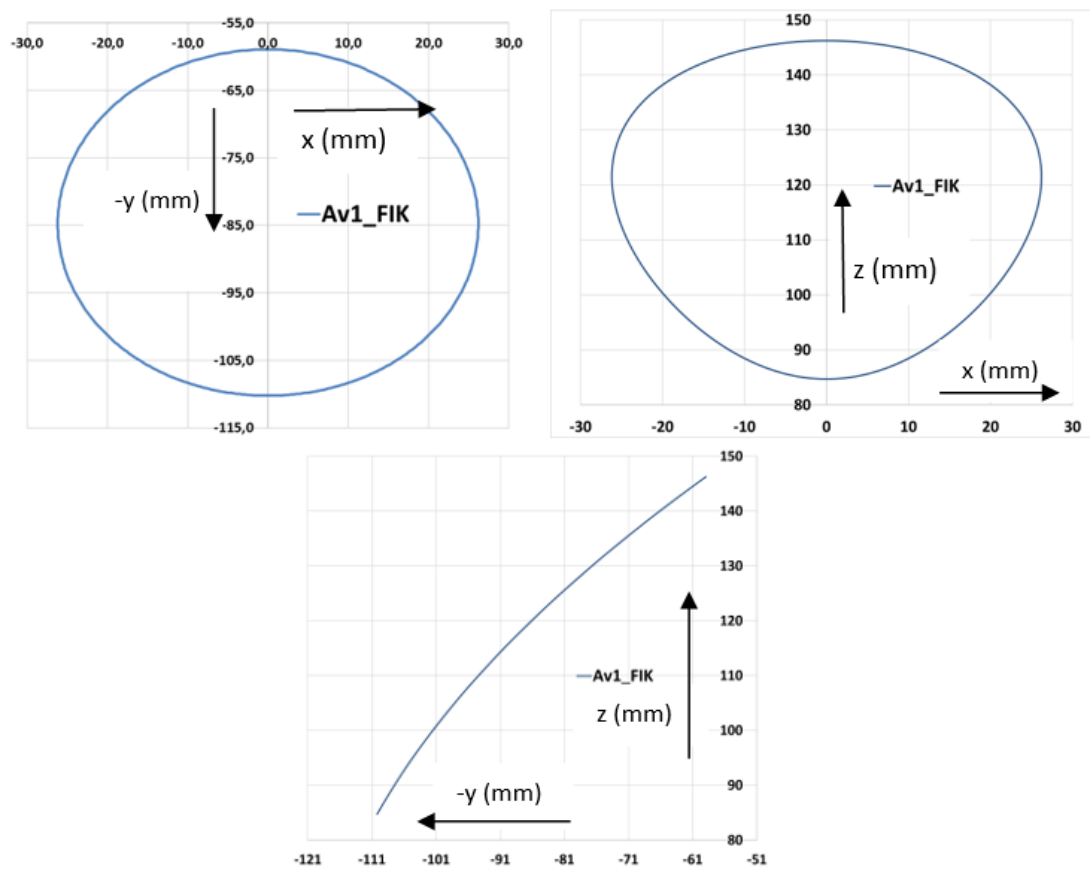

Fig. 7. Projections of trajectories of point (in millimeters) Av1_1 in (at the top, from left side of picture) $x-(-y), x-z$ and $z-y$ plane (at the bottom)

\subsection{Piston stroke}

Courses of the piston strokes will depend on the courses of Av1 points in the vertical $(z)$ direction. The Fig. 8 shows the differences of courses of piston strokes (mechanism with ring) and mechanism FIK (according equation 4).

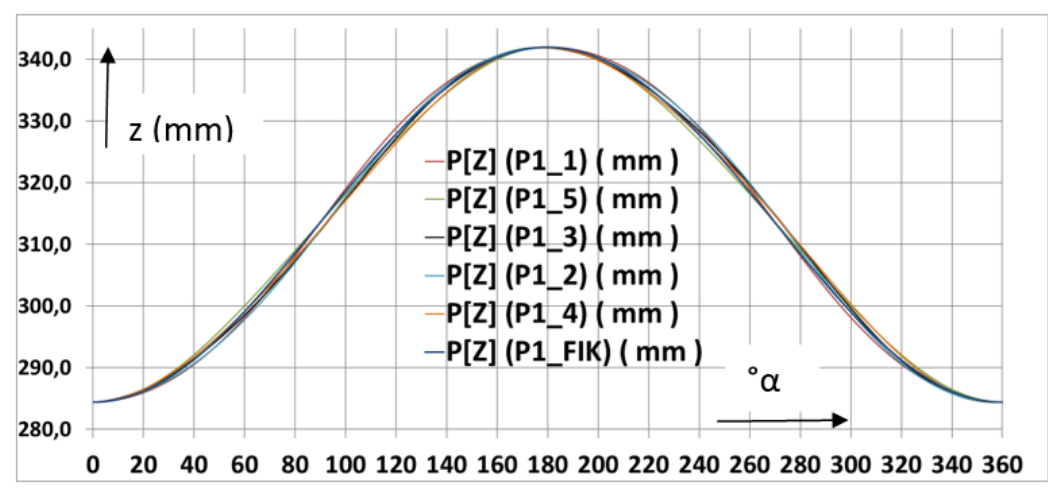

Fig. 8. The sequence of movements of the points P1_1 to P1_5 in z direction according to the angle of rotation of the output shaft 


\subsection{Investigation of the differences in strokes P1 and Av1}

In this case it will be pointed to the differences in the plotted of the piston stroke and points Av1. The curves in Fig. 9 were modified so that the P1 stroke curve was approximately in the Av1 point curve region. This analysis is to show how are these curves different.
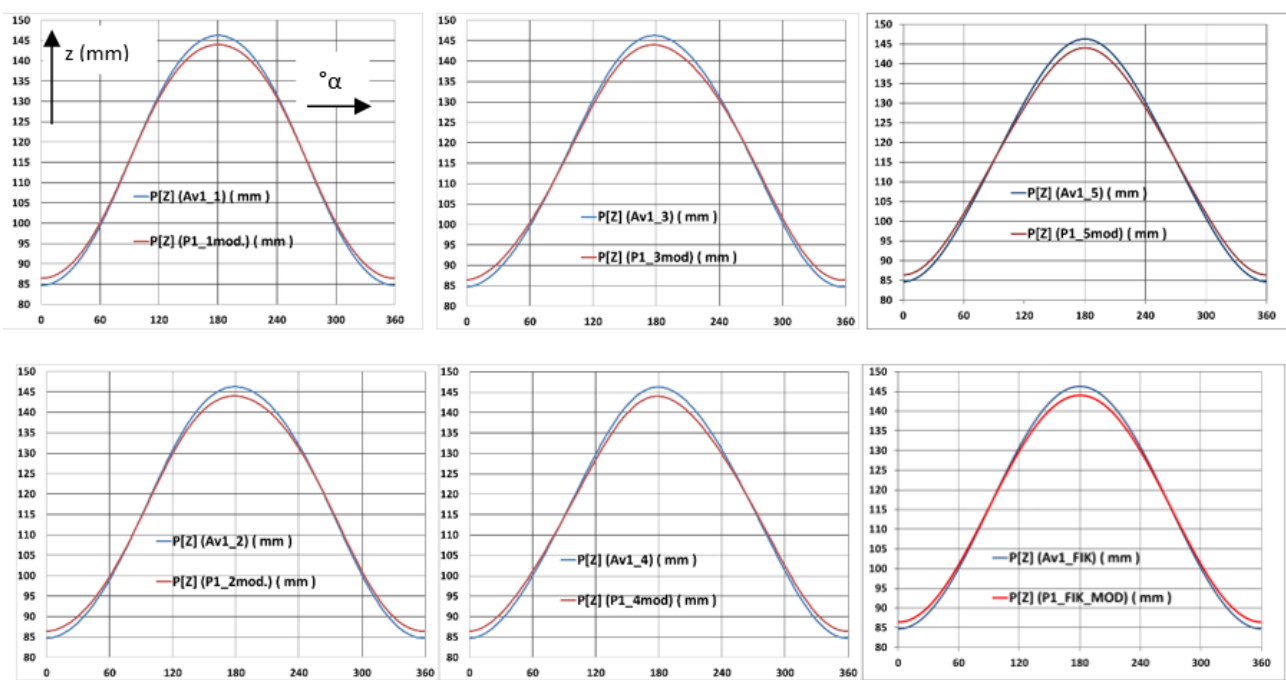

Fig. 9. Courses for P1 and Av1 (horizontal axis ${ }^{\circ} \alpha$, vertical axis $z$ for all diagram)

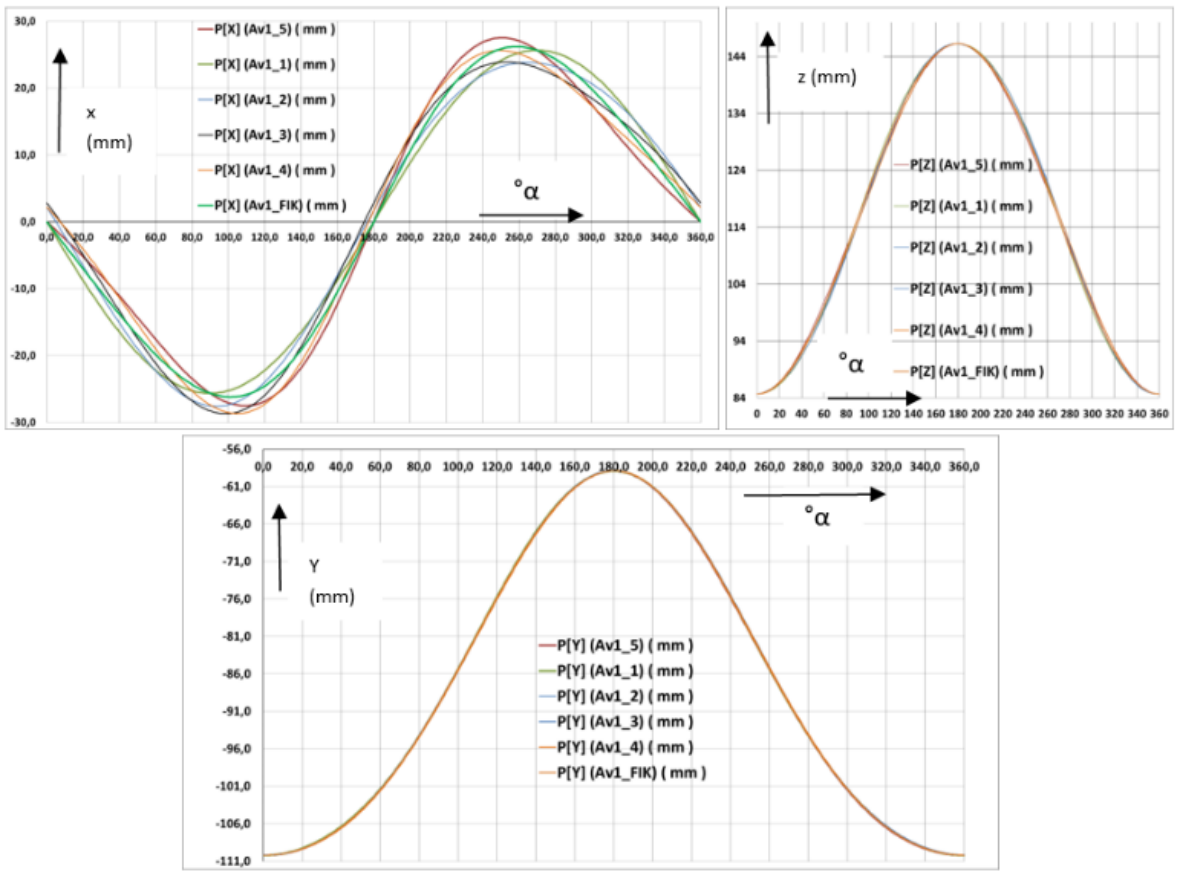

Fig. 10. The sequence of movements of the point Av1_1 to Av1_5 in all three planes according to the angle of rotation of the output shaft 


\subsection{Overall view of the swinging plate points}

In Autodesk Inventor were finally generated trajectories of points in other quadrants of the swinging plate. The aim was an overview of the movement behaviour of the ring mechanism (Fig. 11). From Fig. 11 it can be seen that the trajectory Av1_1 (marked 1) and Av1_9 (marked 9) are similar, mirror-reversed. According to the same procedure as on figure 11, the mechanism FIK would have identical trajectories on the designated circle of the swinging plate.
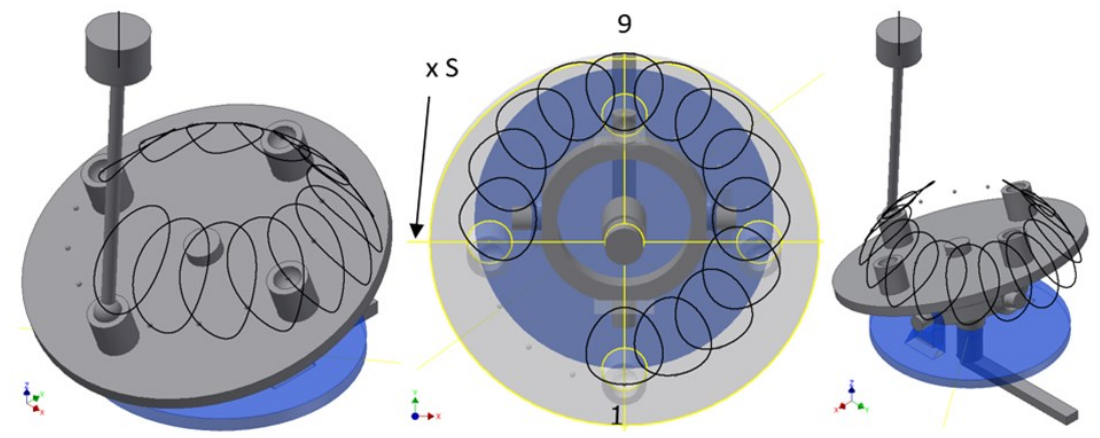

Fig. 11. Overall view of Av1 points in swinging plate ( $x S$ - means axis $x$ of swinging plate)

\section{Conclusion}

The resulting graphs were imported from Autodesk Inventor to Microsoft Excel in case of mechanism with ring and in mechanism FIK were calculated according mathematical model in Microsoft Excel. This analysis shows the differences in kinematic waveforms at the set positions of the points on the plate and the position of the cylinder. From Fig. 6 and Fig. 7, there are visible differences in all planes, but most interesting is projection in $y-z$, between points Av1_1, Av1_5 with Av1_2 to Av1_3. These points also perform the curve (some type of a closed loop) path in this plane. From Fig. 10 it is possible to see again the differences in the projections of points in the direction $x, z$, but in the direction $y$, the deviations are minimal, resp. none. Fig. 9 compares Av1 points and piston strokes (P1) in $z$ direction. From this analysis, it is possible to see only minimal differences in the individual progresses, mainly the Av1_4, P1_4 and Av1_5, P1_5, P1_5 have a slightly different curvature around the angle of rotation of the output shaft by $180^{\circ}$. Fig. 11 shows the waveforms tracks in several quadrants of swinging plate, which can be seen as mirrored projections of these trajectories (points 1 and 9 around the axis $x S$ ). In the difference of the trajectories of the examined points and their courses, depending on the angle of the output shaft, will be speeds and accelerations courses different as well. From this basic analysis it is possible to predict the degree of difficulty in creating a dynamic model and for example in order to creating balancing system on this mechanism. These parameters would have an effect on the torque curve of output shaft depending on its angle of rotation $(\alpha)$, for example in the case of an internal combustion engine. The resulting values generated by Autodesk Inventor were compared with models created with MSC Adams. On reaching the same results, we consider Autodesk Inventor's overall analysis to be reliable. Movement of points and the overall progress of courses will be different from other factors such as the angle of the output shaft breaks (Fig. $2-20^{\circ}$ in our examined model), in positions of points Av1 for a distance of pitch and diameter of the wobble board (Fig. 1, $2-90 \mathrm{~mm}$ ), or positions of cylinders. Therefore, there is necessary to make another analysis of this mechanism. Both of these piston machines have a similar kinematic behaviour, but from the construction 
point of view they are two different mechanisms. Any other analysis, such as design proposal of balancing systems on these machines will be also different.

With this research and development subject deals other publication too $[3,4,5,6]$.

The work was supported by the Cultural and Educational Grant Agency of the Ministry of Education of the Slovak Republic in project No. KEGA 077ŽU-4/2017: Modernization of the Vehicles and engines study program.

This article was supported by the project VEGA 1/0927/15 "Research of the use of alternative fuels and hybrid drives on traction vehicles with aim to reduce fuel consumption and air pollutants production".

\section{References}

1. R. Isteník, Distribution and nonconventional mechanisms of combustion engines. Žilina, (2008)

2. Q. Ling, Yong He, Yuan He, C. Pang, Dynamic response of multibody structure subjected to blast loading. European journal of mechanics a-solids 64 (July-August), 46-57 (2017)

3. D. Barta, J. Saniga, M. Mruzek, M. Kendra, Design of Selected Parts of NonConventional Stirling Engine with FIK Mechanism. The Online J. of Science and Technology 3 (2), 129-139, ISSN 2146-7390 (2013)

4. R. Makaras, J. Sapragonas, A. Keršys, S. Pukalskas, Dynamic model of a vehicle moving in the urban area. Transport, Vilnius Technika 26 (1), 35-42 (2011)

5. R. Isteník, D. Barta, W. Mucha, Influence of the Wheels on the Automobile Dynamics. Communications - Scientific Letters of the University of Zilina 6 (1), 26-28 (2004)

6. J. Dižo, M. Blatnický, B. Skočilasová, Computational Modelling of the Rail Vehicle Multibody System Including Flexible Bodies. Communications - Scientific Letters of the University of Zilina 17 (3), 31-36 (2015) 